\title{
Características testiculares de touros imunizados com vacina anti-hormônio liberador do hormônio luteinizante
}

\author{
Ricardo Zanella(1), Eraldo Lourenso Zanella(2), John Jerry Reeves(1), Jennifer Hernandez ${ }^{(1)}$, \\ Adriana Costa da Motta ${ }^{(2)}$ e David de Avila(1)
}

\begin{abstract}
(1)Washington State University, Department of Animal Sciences, 99164, Pullman, WA, EUA. E-mail: zanellar@wsu.edu, jreeves@colfax.com, jahernandez@wsu.edu, deavila@wsu.edu (2)Universidade de Passo Fundo, Faculdade de Agronomia e Medicina Veterinária, Caixa Postal 611, CEP 99001-970 Passo Fundo, RS. E-mail: ezanella@upf.br, acmotta@upf.br
\end{abstract}

\begin{abstract}
Resumo - $\mathrm{O}$ objetivo deste trabalho foi avaliar a ação imunoesterilizadora de uma vacina anti-hormônio liberador de hormônio luteinizante (LHRH), composta por ovalbumina-LHRH-7 e tiorredoxina-LHRH-7, em touros mestiços Nelore. Vinte e seis touros, com dois anos de idade, foram distribuídos aleatoriamente em dois grupos de 13 animais. No grupo I, os animais receberam uma dose e dois reforços da vacina nos dias 0,141 , e 287 do experimento. No grupo II, os animais não receberam nenhum tratamento (controle). Para avaliar o efeito da vacina nos touros, foi realizada a mensuração da circunferência escrotal no início do experimento e no dia do abate, 741 dias depois. Por ocasião do abate, também foi coletada uma amostra dos testículos para avaliação histológica. O grupo imunizado apresentou circunferência escrotal ao abate de $22 \pm 5,98 \mathrm{~cm}$, menor do que a do grupo controle que foi de $35,6 \pm 2,4 \mathrm{~cm}$. Na análise histológica dos animais do grupo imunizado, foi observada degeneração testicular com ausência de espermatozoides em $85 \%$ dos animais avaliados, os outros $15 \%$ apresentaram redução no número de espermatozoides, em comparação aos animais do grupo controle. A vacina anti-LHRH, com fusão de proteínas, é efetiva na castração imunológica de touros e deve ser considerada como alternativa para utilização na produção bovina extensiva no Brasil.
\end{abstract}

Termos para indexação: Bos taurus indicus, imunoesterilização, LHRH, touros Nelore.

\section{Testicular characteristics of bulls immunosterilized with anti-luteinizing hormone-releasing hormone vaccine}

\begin{abstract}
The objective of this study was to evaluate the immunosterilization action of the anti-luteinizing hormone-releasing hormone (LHRH) vaccine, composed with ovalbumin-LHRH-7 and thioredoxin-LHRH-7, in Nelore-cross bulls. Twenty-six 2-year old bulls were randomly assigned in two groups of 13 animals each. The animals of group I received a primary and two booster injections of the vaccine on days 0,141 , and 287 of the experiment. In group II, the control group, the bulls did not receive any type of treatment. Scrotal circumference was measured in the beginning of the experiment and at slaughter, after 741 days. A testicular sample was collected at slaughter and processed for histological evaluation. The scrotal circumference in the immunized group was smaller, $22 \pm 5.98 \mathrm{~cm}$, compared to the one of the control group $(35.6 \pm 2.4 \mathrm{~cm})$, at slaughter. Histological analyses of the testis showed testicular degeneration and absence of sperms in $85 \%$ of the animals in the treated group, and a reduced number of sperms in the other $15 \%$, in comparison to the control group. The vaccine anti-LHRH with protein fusion is effective in immune castration of bulls and should be considered as an alternative tool for extensive livestock production in Brazil.
\end{abstract}

Index terms: Bos taurus indicus, immunosterilization, LHRH, Nelore bulls.

\section{Introdução}

A imunização contra o hormônio liberador de hormônio luteinizante (LHRH) vem sendo amplamente pesquisada, pelo grande potencial de suprimir de maneira eficaz a capacidade reprodutiva de animais (Ülker et al., 2009a, 2009b). Porém, o uso de antígenos peptídeos, como o LHRH de pequena massa molecular, apresenta baixa capacidade imunogênica (Reeves et al., 1989). Estudos iniciais descreveram que a utilização de LHRH, conjugada à albumina sérica bovina (BSA), atrofia e, consequentemente, inativa a função das gônadas de coelhos (Arimura et al., 1973). Além disso, foram também demonstrados a inibição da gametogênese e o bloqueio do comportamento reprodutivo de várias espécies de mamíferos (Falvo 
et al., 1986). A imunização ativa contra o LHRH serviu como método para introduzir uma barreira imunológica entre o hipotálamo e a pituitária anterior que, mais especificamente, neutraliza o LHRH na vasculatura porta hipotálamo-hipofiseal (Adams \& Adams, 1986; Ülker et al., 2009a).

$\mathrm{O}$ grande desafio de vacinas quimicamente conjugadas é a ausência de moléculas previsíveis e similares entre os lotes de produção, o que dificulta a padronização do antígeno e, consequentemente, da resposta imune. Uma alternativa para contornar este problema tem sido o uso de proteínas recombinantes, nas quais o LHRH é sintetizado em fusão com diversas proteínas na vacina (Quesnell et al., 2000). Zee et al. (1995) desenvolveram uma vacina baseada em fímbrias recombinantes de Escherichia coli, que contêm sequências repetidas de LHRH, cujo gene LHRH foi inserido, por meio da técnica de DNA recombinante, nos plasmídeos que codificam a expressão dessa estrutura na bactéria (Broekhuijsen et al., 1987). Esta vacina mostrou-se efetiva, induziu a produção de altos títulos de anticorpos anti-LHRH e suprimiu o crescimento testicular em bovinos jovens (Zee et al., 1995).

Os bovinos machos inteiros, destinados à engorda na região Centro-Oeste brasileira, são mantidos em grupos no pasto, o que geralmente leva a um comportamento mais agressivo, em razão da idade e das elevadas concentrações de testosterona nesses animais. A supressão da testosterona, por meio da remoção das gônadas, tem como objetivo principal tornar os animais mais dóceis, para facilitar o manejo do lote. A castração cirúrgica ou orquiectomia é uma das alternativas comumente utilizadas, entretanto, é considerada como um procedimento traumático e necessita de técnico qualificado para sua realização, para minimizar o sofrimento dos animais (uso de anestésicos), o que também está relacionado a questões de cunho ético-profissional. Além disso, como é um processo cirúrgico, há necessidade de acompanhamento individual no período pós-operatório, cuja falha poderá causar perda de animais em razão de complicações, como: inflamação, infecção, miíases, entre outras (Oliveira et al., 2005).

O objetivo deste trabalho foi avaliar a ação imunoesterilizadora de uma vacina anti-hormônio liberador do hormônio luteinizante (LHRH), composta por ovalbumina-LHRH-7 e tiorredoxina-LHRH-7, em touros mestiços Nelore.

\section{Materiais e Métodos}

A síntese de LHRH recombinante, em fusão com as proteínas ovalbumina e tiorredoxina, foi realizada conforme descrito por Zhang et al.(1999). A construção gênica utilizada para a produção do composto com ovalbumina possuía sete sequências do gene do LHRH, inseridas em quatro diferentes posições do fragmento do gene da ovalbumina, enquanto para o composto que possui a tiorredoxina, sete sequências gênicas do hormônio foram introduzidas em três diferentes posições no gene da tiorredoxina. A linhagem BL21(DE3) de Escherichia coli foi utilizada para a expressão das proteínas. A purificação da proteína de fusão com LHRH foi realizada por meio de cromatografia por afinidade ao níquel. As proteínas purificadas foram combinadas em quantidades equivalentes, para chegar à concentração final de $1,5 \mathrm{mg}$ de LHRH por dose; foram, então, emulsificadas em adjuvante completo de Freund modificado (CakBiochem, San Diego, CA, Estados Unidos), para a primeira dose da imunização, ou em adjuvante incompleto de Freund, para os dois reforços subsequentes.

Foram utilizados 26 touros Nelore mestiços, com aproximadamente dois anos de idade, em maio de 2001, mantidos na fazenda Colorado, em Bom Jesus do Araguaia $\left(12^{\circ} 08^{\prime} 08^{\prime \prime S}\right.$ e $\left.51^{\circ} 41^{\prime} 24^{\prime \prime} \mathrm{W}\right)$, no Estado do Mato Grosso. O clima predominante é o tropical continental, com chuvas distribuídas ao longo do ano e maiores precipitações pluviais em dezembro, janeiro e fevereiro. A média de precipitação anual na região é de $1.750 \mathrm{~mm}$, e a temperatura média do ar é de $22^{\circ} \mathrm{C}$.

Os animais tinham livre acesso à pastagem de Brachiaria brizantha, sal mineralizado e água, durante todo o período do experimento. $\mathrm{O}$ abate dos animais estava previsto, inicialmente, para os três anos de idade (um ano após a primovacinação), entretanto, em consequência das condições climáticas desfavoráveis, os animais não atingiram o peso de abate esperado e permaneceram por mais um ano na propriedade. Os animais foram separados aleatoriamente em dois grupos; o grupo I (imunizado) foi composto por 13 touros que receberam uma aplicação subcutânea da vacina anti-LHRH, no dia 0 , e dois reforços a intervalos de aproximadamente 140 dias (dias 141 e 287); o grupo II (controle) foi composto por 13 touros que não receberam nenhum tipo de tratamento. Mensurações do peso vivo e da circunferência escrotal dos animais foram realizadas no dia 0 , aos 454 dias de intervalo do 
último reforço da vacina, e no momento do abate dos animais, aos 741 dias após a primoimunização.

Os testículos foram coletados ao abate, e um fragmento de aproximadamente um grama da porção mediana do testículo foi imerso em fixativo de Bowin por pelo menos sete dias, lavado em etanol a $70 \%$, processado e embebido em parafina, para o corte histológico de 4-5 $\mu \mathrm{m}$ de espessura. As lâminas com os cortes histológicos foram coradas com hematoxilina e eosina (H\&E) e, em seguida, analisadas em microscópio óptico para avaliação morfológica.

As medidas de circunferência escrotal e peso vivo foram submetidas ao teste $t$ de Student, para verificação da existência de diferenças significativas entre os parâmetros, nos dois grupos analisados. Posteriormente, foi feita a análise de variância para verificação da existência de interação entre tempo e circunferência escrotal. Todas as análises estatísticas foram realizadas com o programa $\mathrm{R}$ ( $\mathrm{R}$ Development Core Team, 2009).

\section{Resultados e Discussão}

As medidas da circunferência escrotal dos testículos de touros Nelore mestiços, criados extensivamente, foram similares nos grupos vacinados e controle, no dia 0 (Tabela 1). Contudo, ocorreu aumento significativo deste parâmetro no grupo controle, em relação ao grupo vacinado, aos 741 dias. Os animais no grupo controle apresentaram ganho de peso maior durante o período experimental, com peso vivo ao abate superior ao do grupo imunizado. O aumento de peso dos animais inteiros, em relação aos imunizados, ocorreu, possivelmente, em razão da maior ação hormonal proveniente dos hormônios androgênicos, entre eles a testosterona, produzida nos testículos (Field, 1971). Freitas et al. (2008) encontraram resultados similares e demonstraram que bovinos castrados

Tabela 1. Circunferência escrotal e peso vivo em touros Nelore mestiços, imunocastrados com vacina anti-hormônio liberador do hormônio luteinizante (vacinados) ${ }^{(1)}$ e inteiros (controle), no início (dia 0) e ao final do experimento (741 dias).

\begin{tabular}{llllll}
\hline Tratamento & \multicolumn{2}{c}{ Circunferência escrotal $(\mathrm{cm})$} & & \multicolumn{2}{c}{ Peso vivo $(\mathrm{kg})$} \\
\cline { 2 - 3 } \cline { 5 - 6 } & \multicolumn{1}{c}{0 dias } & 741 dias & & 0 dias & 741 dias \\
\hline Controle $(\mathrm{n}=13)$ & $21,54 \pm 2,5$ & $35,6 \pm 2,4$ & & $256 \pm 24$ & $576 \pm 39$ \\
Vacinados $(\mathrm{n}=13)$ & $21,19 \pm 3,16$ & $22,0 \pm 5,98 * *$ & & $248 \pm 22$ & $507 \pm 55^{* *}$ \\
\hline (1) Touros vacinados com anti-LHRH aos 0, 141 e 287 dias do experimento. \\
**Significativo a 1\% de probabilidade na coluna.
\end{tabular}

cirurgicamente apresentaram peso vivo entre $5 \mathrm{e}$ $7,5 \%$ menor que os bovinos inteiros. Todavia, quando bovinos castrados cirurgicamente foram comparados a animais imunizados, não foram observadas diferenças significativas entre os grupos (Cook et al., 2001; Ribeiro et al., 2004).

A degeneração testicular, com descamação do epitélio seminífero, foi observada em análises histológicas nas amostras do grupo vacinado. Além disso, em $85 \%$ das amostras desse grupo, observou-se a ausência total de espermatozoides, o que mostra a disfunção das células de Sertoli, causada, provavelmente, pela ação da vacina anti-LHRH ao inibir a secreção de FSH e LH hipofiseal. Nas amostras restantes (15\%), foi verificada a redução do número de espermatozoides, provavelmente em consequência da retomada da função das células de Sertoli, após a aplicação do último reforço da vacina ou pela inibição parcial da espermatogênese. Efeito semelhante foi observado por Robertson et al. (1982), que imunizaram bezerros com uma vacina anti-LHRH e verificaram a supressão das funções gonadais e do comportamento sexual dos animais, que retornaram à normalidade seis meses após a última dose. No grupo II (controle), a análise histopatológica indicou a presença de espermatozoides (espermatogênese) em $100 \%$ das amostras, sem alteração na arquitetura dos túbulos seminíferos.

A diminuição da circunferência escrotal em touros Nelore mestiços, observadas no presente estudo em decorrência da imunização com a vacina anti-LHRH, também foi observada em outras raças e espécies (Huxsoll et al., 1998; Cook et al., 2000; Ülker et al., 2009a, 2009b). A inibição da função reprodutiva dos bovinos, causada pela imunoesterilização com vacina anti-LHRH, mostrou-se efetiva de acordo com os parâmetros previamente descritos por Arimura et al. (1973), caracterizados pela redução da circunferência testicular e pela diminuição e ausência de espermatozoides viáveis nos túbulos seminíferos.

A utilização de diferentes adjuvantes deve ser testada em vacinas para imunocastração em touros, para se buscar o bloqueio prolongado no sistema de regulação da espermatogênese (hipotálamo-hipofisário-gonadal). Conforti et al. (2008) demonstraram que o uso de oligodeoxinucleotídeos sintéticos, baseados em citosina e guanina $(\mathrm{CpG})$, como adjuvante para a imunoesterilização em novilhas de raças europeias, 
produziu resposta imunológica maior que o adjuvante completo de Freund. Além disso, futuros estudos devem ser realizados para a avaliação da resposta a diferentes concentrações de LHRH, visto que, no presente trabalho, a vacina não apresentou eficácia de $100 \%$ na supressão da espermatogênese, com uso da concentração de 1,5 mg por dose. Conforti et al. (2008) demonstraram que o uso da vacina anti-LHRH, com concentração final de 3,4 mg de LHRH, resultou em maiores concentrações de anticorpos contra o LHRH, em comparação às diferentes doses, que variaram de 1,5 a 7,6 mg de LHRH, além de ter resultado na redução significativa no peso do trato reprodutivo de novilhas, em comparação a doses totais inferiores a $1,5 \mathrm{mg}$ de LHRH.

\section{Conclusão}

A imunocastração de touros Nelore mestiços, pela ação imunoesterilizadora da vacina anti-hormônio liberador do hormônio luteinizante, é uma alternativa viável de método contraceptivo e de controle comportamental, por meio da supressão da síntese de testosterona.

\section{Referências}

ADAMS, T.E.; ADAMS, B.M. Gonadotrope function in ovariectomized ewes actively immunized against gonadotropin-releasing hormone $(\mathrm{GnRH})$. Biology of Reproduction, v.35, p.360-367, 1986.

ARIMURA, A.; SATO, H.; KUMASAKA, T.; WOROBEC, R. B. fun; DEBELJUK, L.; DUNN, J.; SCHALLY, A.V. Production of antiserum to LH-releasing hormone (LH-RH) associated with gonadal atrophy in rabbits: development of radioimmunoassays for LH-RH. Endocrinology, v.93, p.1092-1103, 1973.

BROEKHUIJSEN, M.P.; VAN RIJN, J.M.M.; BLOM, A.J.M.; POUWELS, P.H.; ENGER-VALK, B.E.; BROWN, F.; FRANCIS. M.J. Fusion proteins with multiple copies of the major antigenic determinant of foot-and-mouth disease virus protect both the natural host and laboratory animals. Journal of General Virology, v.68, p.3137-3143, 1987.

CONFORTI, V.A.; AVILA D.M. de; CUMMINGS, N.S.; ZANELLA, R.; WELLS, K.J.; ÜLKER, H.; REEVES, J. CpG motif-based adjuvant as a replacement for Freund's complete adjuvant in a recombinant LHRH vaccine. Vaccine, v.26, p.907-913, 2008.

COOK, R.B.; POPP, J.D.; KASTELIC, J.P.; ROBBINS, S.; HARLAND, R. The effects of active immunization against GnRH on testicular development, feedlot performance, and carcass characteristics of beef bulls. Journal of Animal Science, v.78, p.2778-2783, 2000.
COOK, R.B.; POPP, J.D.; MCALLISTER, T.A.; KASTELIC, J.P.; HARLAND, R. Effects of immunization against GnRH, melengestrol acetate, and a trenbolene acetate/estradiol implant on growth and carcass characteristics of beef heifers. Theriogenology, V.55, p.973-981, 2001.

FALVO, R.E.; CHANDRASHEKAR, V.; ARTHUR, R.D.; KUENSTLER, A.R.; HASSON, T.; AWONIYI, C.; SCHANBACHER, B.D. Effect of active immunization against LHRH or LH in boars: reproductive consequences and performance traits. Journal of Animal Science, v.63, p.986-994, 1986.

FIELD, R.A. Effect of castration on meat quality and quantity. Journal of Animal Science, v.32, p.849-856, 1971.

FREITAS, A.K. de; RESTLE, J.; PACHECO, P.S.; PADUA, J.T.; LAGE, M.E.; MIYAGI, S.; SILVA, G.F.R. da. Características de carcaças de bovinos Nelore inteiros vs castrados em duas idades, terminados em confinamento. Revista Brasileira de Zootecnia, v.37, p.1055-1062, 2008.

HUXSOLL, C.C.; PRICE, E.O.; ADAMS, T.E. Testis function, carcass traits, and aggressive behavior of beef bulls actively immunized against gonadotropin-releasing hormone. Journal Animal Science, v.76, p.1760-1766, 1998.

OLIVEIRA, M.C. de S.; BRITO, L.G. Miíases dos bovinos. São Carlos: Embrapa Pecuária Sudeste, 2005. 10p. (Embrapa Pecuária Sudeste. Comunicado Técnico, 56).

QUESNELL, M.M.;ZHANG, Y.H.;AVILA, D.M.de;BERTRAND, K.P.; REEVES, J.J. Immunization of male mice with luteinizing hormone-releasing hormone fusion proteins reduces testicular and accessory sex gland function. Biology of Reproduction, v.63, p.347-353, 2000.

R DEVELOPMENT CORE TEAM. R: a language and environment for statistical computing. Vienna: R Foundation for Statistical Computing, 2009. Disponível em: <http://www.R-project.org>. Acesso em: 06 nov. 2009.

REEVES, J.J.; CHANG, C.F.; AVILA, D.M. de; GRIEGER, D.M.; JOHNSON, H.E.; ROBERTS, A.J. Vaccines against endogenous hormones: a possible future tool in animal production. Journal of Dairy Science, v.72, p.3363-3371, 1989.

RIBEIRO, E.L. de A.; HERNANDEZ, J.A.; ZANELLA, E.L.; SHIMOKOMAKI, M.; PRUDÊNCIO-FERREIRA, S.H.; YOUSSEF, E.; RIBEIRO, H.J.S.S.; BOGDEN, R.; REEVES, J.J. Growth and carcass characteristics of pasture fed LHRH immunocastrated, castrated and intact Bos indicus bulls. Meat Science, v.68, p.285-290, 2004.

ROBERTSON, I.S.; FRASER, H.M.; INNES, G.M.; JONES, A.S. Effect of immunological castration on sexual and production characteristics in male cattle. Veterinary Record, v.111, p.529-531, 1982.

ÜLKER, H.; KÜÇÜK, M.; YILMAZ, A.; YÖRÜK, M.; ARSLAN, L.; AVILA, D.M. de; REEVES, J.J. Changes in testicular development, ultrasonographic and histological appearance of the testis in buck kids immunized against LHRH using recombinant LHRH fusion protein. Reproduction in Domestic Animals, v.44, p.37-43, 2009a. 
ÜLKER, H.; YILMAZ, A.; KARAKUS, F.; YÖRÜK, M.; BUDAG, C.; AVILA, D.M. de; REEVES, J.J. LHRH fusion protein immunization alters testicular development, ultrasonographic and histological appearance of ram testis. Reproduction in Domestic Animals, v.44, p.593-599, 2009 b.

ZEE, A. van der; NOORDEGRAAF, C.V.; BOSCH, H. van den; GIELEN, J.; BERGMANS, H.; HOEKSTRA, W.; DIE, I. van. P-fimbriae of Escherichia coli as carriers for gonadotropin releasing hormone: development of a recombinant contraceptive vaccine. Vaccine, v.13, p.753-758, 1995.

ZHANG,Y.Z.; ROZELL, T.G.;AVILA, D.M.de;BERTRAND, K.P.; REEVES, J.J.. Development of recombinant ovalbumin-luteinizing hormone releasing hormone as a potential sterilization vaccine. Vaccine, v.17, p.2185-2191, 1999.

Recebido em 22 de fevereiro de 2009 e aprovado em 15 de setembro de 2009 